\section{Dr. Takizawa, et al reply}

To the Editor:

We appreciate Dr. Rothschild's comments ${ }^{1}$ on our paper ${ }^{2}$. Regarding the diagnosis of rheumatoid arthritis (RA) of this patient, she met the 6 points of the 2010 American College of Rheumatology/European League Against Rheumatism classification criteria for RA (6 points and over are classified as definite RA, and she had joint involvement $>10$ and abnormal acute-phase reactants) ${ }^{3}$. She did not have inflammatory back pain, which is characteristic of spondyloarthritis.

The computed tomography scan and the magnetic resonance imaging demonstrated calcification of the left alar ligament, and showed neither evidence of ossification of the posterior longitudinal ligament nor other abnormalities.

Dr. Rothschild's comments that more than $20 \%$ of Teleoceras had spondyloarthritis $(\mathrm{SpA})$, and that the alar ligament calcification may be caused by $\mathrm{SpA}$ and traumatic injuries ${ }^{4}$, are of great interest. The patient had no history of traumatic injury and therefore we could not obtain this information.

NAOHO TAKIZAWA, MD, Department of Rheumatology, Chubu Rosai Hospital; ATSUSHI NOMURA, MD, Department of Rheumatology, Chubu
Rosai Hospital; YOSHIRO FUJITA, MD, Department of Rheumatology, Chubu Rosai Hospital, Nagoya, Japan. Address correspondence to Dr. N. Takizawa, Department of Rheumatology, Chubu Rosai Hospital, Minato-ku Komei 1-10-6, Nagoya, Aichi 455-8530, Japan. E-mail: ttkkzzww5959@gmail.com

\section{REFERENCES}

1. Rothschild BM. Alar and transverse ligament calcification and crown dens. J Rheumatol 2016;43:1251-2.

2. Takizawa N, Nomura A, Fujita Y. Rare cause of nuchal pain: calcification of the alar ligament. J Rheumatol 2016;43:177-8.

3. Aletaha D, Neogi T, Silman AJ, Funovits J, Felson DT, Bingham CO 3rd, et al. 2010 Rheumatoid arthritis classification criteria: an American College of Rheumatology/European League Against Rheumatism collaborative initiative. Ann Rheum Dis 2010; 69:1580-8

4. Rothschild BM, Prothero DR, Rothschild C. Origins of spondyloarthropathy in Perissodactyla. Clin Exp Rheum 2001;19:628-32.

J Rheumatol 2016;43:6; doi:10.3899/jrheum.160375 